\title{
Pituitary Apoplexy and Aortic Dissection
}

\author{
RN Mudaliar', A Golash², K Kaushal', SJ Howell' \\ Departments of Endocrinology ${ }^{1}$ and Neurosurgery ${ }^{2}$, Lancashire Teaching Hospitals NHS Foundation Trust, \\ Sharoe Green Lane, Preston, Lancashire
}

\section{Introduction}

Pituitary apoplexy is a rare but life-threatening clinical syndrome characterised by acute neuro-ophthalmological features caused by haemorrhage and/or infarction of the pituitary gland. Although many precipitating factors are known, most apoplectic episodes occur spontaneously. Hypertension is the commonest precipitating factor, others being major surgery $(\mathrm{CABG})$, dynamic pituitary testing, oestrogen therapy, anticoagulation therapy, coagulopathies, pregnancy and head trauma.

Patients who had tumour infarction had generally less severe clinical symptoms and a longer course before presenting for medical care but a better outcome than those who had haemorrhage or haemorrhagic infarction of the adenoma'.

Apart from patients with worsening neurological symptoms in whom surgery is indicated, it is unclear currently for the majority of patients whether conservative or surgical management carries the best outcome ${ }^{2}$.

\section{Case}

A 59 year old gentleman presented in 2005 with a 12 month history of a bitemporal hemianopia. An MR scan revealed a pituitary macroadenoma. When he was reviewed in the pituitary clinic repeat assessment showed improvement of the visual field defect. His baseline pituitary hormonal profile was normal. In the absence of any signs of optic chiasmal compression and given that he had significant co-morbidity by way of CCF, a watch and wait policy was adopted. He remained clinically and radiologically stable for the next 5 years.

In 2010, he was admitted to a neighbouring hospital with acute aortic dissection. This was managed conservatively and was followed by a protracted period of rehabilitation. During his recovery, he experienced substantial nausea, anorexia and significant weight loss. He was also noted to have a bitemporal hemianopia and was therefore assessed in the pituitary clinic. His visual field defect had almost resolved with only a left inferotemporal defect persisting. A pituitary MRI scan showed marked reduction in size of pituitary adenoma and drooping of the optic chiasm. Endocrine assessment revealed TSH, gonadotropin and partial ACTH deficiency. It was felt likely that he had developed pituitary infarction secondary to aortic dissection. He was established on appropriate hormonal replacement. He subsequently underwent aortic valve replacement and aortic repair under steroid cover. He remains stable although there has been intermittent fluctuation in visual symptoms.

\begin{tabular}{|c|c|c|c|}
\hline \multicolumn{4}{|c|}{ Investigations } \\
\hline \multicolumn{4}{|c|}{ Endocrine Assessment } \\
\hline Pituitary Profile & & Baseline - 2005 & Post Pitutitary Infarction -2010 \\
\hline \multirow{2}{*}{ TFT's } & TSH (mU/L) & 0.88 & 1.75 \\
\hline & fT4 (pmollL) & 14.9 & 9.8 \\
\hline \multicolumn{2}{|l|}{ Prolactin (mU/L) } & 641 & 170 \\
\hline \multicolumn{2}{|l|}{ FSH (IU/L) } & 4.1 & 4 \\
\hline \multicolumn{2}{|l|}{ LH (IU/L) } & 6.1 & 4.5 \\
\hline \multicolumn{2}{|l|}{ IGF-1 (nmol/L) } & 15 & 11 \\
\hline \multicolumn{2}{|c|}{ Cortisol - Random (nmol/L) } & 697 & 112 \\
\hline \multirow{2}{*}{$\begin{array}{l}\text { Short Synacthen Test } \\
\text { (sST) }\end{array}$} & $0^{\prime}$ & - & 173 \\
\hline & $30^{\prime}$ & - & 491 \\
\hline \multicolumn{2}{|c|}{ Urinary Free Cortisol (24 hour) } & Normal & - \\
\hline \multicolumn{2}{|l|}{ Testosterone (nmol/L) } & 13.2 & 4.8 \\
\hline \multicolumn{2}{|l|}{ MRI Brain } & $\begin{array}{l}\text { Pitutitary Macroadenoma. No } \\
\text { Optic Chiasmal compression }\end{array}$ & Empty Sella \\
\hline \multicolumn{2}{|l|}{ Visual Fields } & Normal & $\begin{array}{l}\text { Mild left ifferotemporal } \\
\text { abnormality }\end{array}$ \\
\hline
\end{tabular}

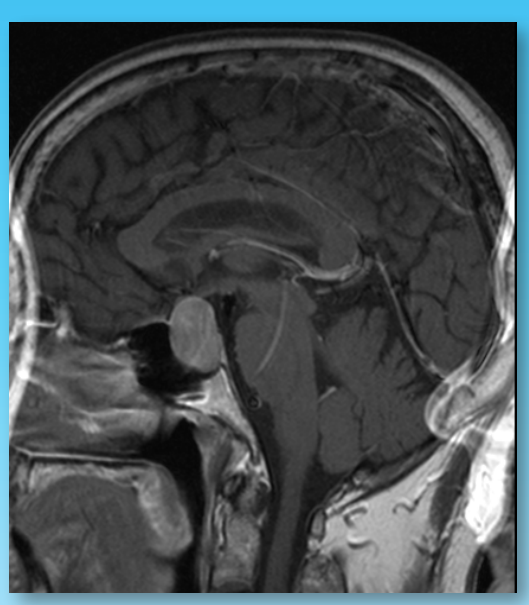

Base-line Scan 2005

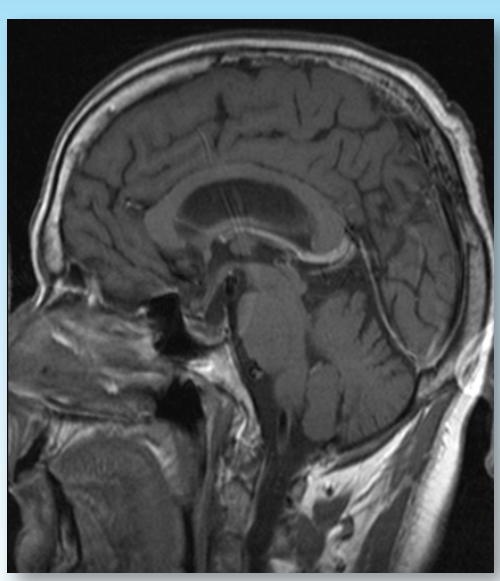

Post Pituitary Infarction -2010

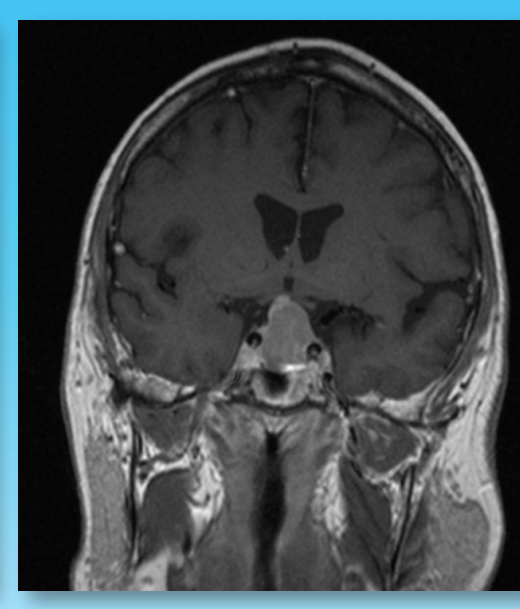

Scan - 2008

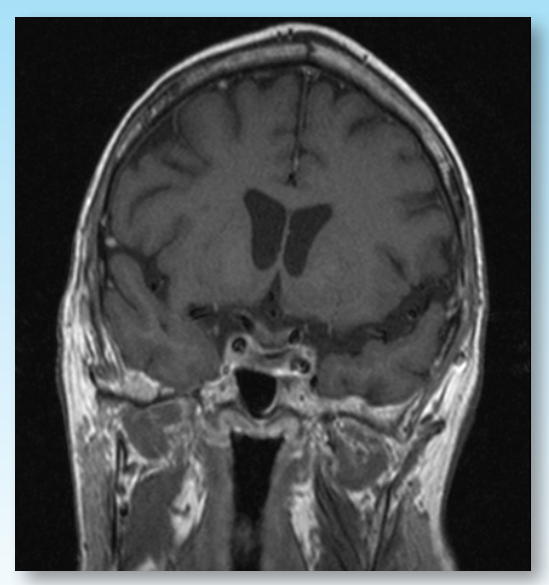

Post Pituitary Infarction -2010

\section{Discussion}

The pathophysiological changes that lead to pituitary apoplexy are still open to speculation. Fluctuations in blood pressure during hypotension and similarly transient increases in intracranial pressure result in reduced blood flow within the pituitary causing hypo-perfusion of the pituitary gland $^{3}$. Sudden alterations in the critical perfusion pressure to the adenoma is a significant predisposing factor ${ }^{4}$. We suggest the likely explanation for hypopituitarism in our case was pituitary infarction as a result of sudden hypotension secondary to aortic dissection.

The deterioration of visual acuity and bitemporal hemianopia could be explained by acute pituitary infarction causing sellar oedema and chiasmal compression. Subsequent tumour shrinkage could explain the subsequent improvement in visual fields ${ }^{5}$.

The unrecognised borderline cortisol deficiency following pituitary infarction may have explained the prolonged recovering from illness and weight loss.

\section{Conclusions}

The partial hypopituitarism and shrinkage of the pituitary tumour in this case is likely to be explained by pituitary infarction caused by sudden alterations in critical perfusion pressure as a result of acute aortic dissection on a background of cardiac failure. Timely recognition and early hormonal replacement would likely have speeded up recovery from the dissection

\section{References}

Pituitary apoplexy: do histological features influence the clinical presentation and outcome? - Semple et al, Neurosurg. 2006; 104:931-937.

2. UK guidelines for the management of pituitary apoplexy- Rajasekaran $\mathrm{S}$ et al Clinical Endocrinology. 2011; 74(1):9-20.

. Precipitating factors in pituitary apoplexy - V Biousse et al. J Neurol Neurosurg Psychiatry 2001; 71:542-545)

4. Pressure and blood flow in pituitary adenomas measured during transsphenoidal surgery- Kruse et al, Br J Neurosurg. 1992; 6: 333-341.

Optic chiasmal herniation--an under recognized complication of dopamine agonist therapy for macroprolactinoma. Jones SE Clin Endocrinol (Oxf) 2000 Oct; 53(4):529-34

Lancashire Teaching Hospitals W/HS RN Mudaliar

NHS Foundation Trust

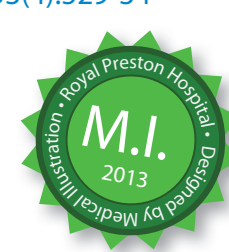

